\title{
Adaptive Maximum Power Control Based on Optimum Torque Method for Wind Turbine by Using Fuzzy-Logic Adaption Mechanisms during Partial Load Operation
}

\author{
Youcef Saidi, Abdelkader Mezouar ${ }^{1}$, Yahia Miloud², Brahim Brahmi ${ }^{3}$, \\ Kamel Djamel Eddine Kerrouche ${ }^{4,5}$, Mohammed Amine Benmahdjoub ${ }^{1}$ \\ 1 Electro-Technical Engineering Laboratory (LGE), Faculty of Technology, Tahar Moulay University, P. O. B. 138, 20000 Ennasr, \\ Saida, Algeria \\ 2 Department of Electrical Engineering, Faculty of Technology, Tahar Moulay University, P. O. B. 138, 20000 Ennasr, Saida, Algeria \\ ${ }^{3}$ Department of Electrical Engineering, École de technologie supérieure, P. O. B. H3C 1K3, 1100 Montreal, Canada \\ ${ }^{4}$ School of Automation on Science and Electrical Engineering, Beihang University, Haidian District, Beijing 100191, Xueyuan \\ Road 37, China \\ ${ }^{5}$ Satellite Development Center CDS, P. O. B. 4065, 31000 Ibn Rochd USTO, Oran, Algeria \\ *Corresponding author, e-mail: saidi_youcef_20@yahoo.com
}

Received: 20 October 2019, Accepted: 03 December 2019, Published online: 27 January 2020

\begin{abstract}
This paper aims to increase the effectiveness of the Maximum Power Control (MPC) strategy by using a new Adaptive Maximum Power Control method (AMPC) for maximizing the power delivered by the Wind Turbine System (WTS) during partial load operation whatever the disturbances caused by variations in wind profile. The AMPC is applied to one of the frequently used Maximum Power Point Tracking (MPPT) methods called as Optimum Torque (OT) MPPT algorithm. Furthermore, the proposed AMPC strategy aims to optimize the wind energy captured by the WTS during partial load operation under rating wind speed, using Fuzzy-Logic as Adaption Mechanisms (AMPC-FLC). Additionally, the performances of the proposed improved OT-MPPT method based on AMPC-FLC are compared to the OT-MPPT method based on Conventional Maximum Power Control (CMPC-PI) under the same conditions. The robustness, dynamic performance, and fast approximation of the optimal value are proved with the numerical simulations under MATLAB/Simulink® software.
\end{abstract}

Keywords

Wind Turbines System (WTS), Adaptive Maximum Power Control (AMPC), Optimum Torque (OT), Fuzzy Logic Control (FLC), partial load operation

\section{Introduction}

Wind Power Generation System (WPGS) draws a lot of attention because of its clean source, sustainable energy, slight impact on the environment, as well as its cost competitiveness compared to non-renewable resources [1]. In addition, the WPGS is considered the most cost-effective according to all renewable energy sources [2]. The WTS can be operated at constant speed or variable speed. Variable speed turbine-based Aerodynamic Wind Systems have been used for a variety of reasons [3]. Of the currently available WPGS, the market share of variable speed turbine-based Aerodynamic Wind Systems is steadily increasing, as changes in wind speed are followed by speed control of the shaft, which allows the WTS to operate at its full speed whatever the changes in wind speed [4].
Getting as much wind energy as possible in the shortest possible time is one of the most major problems in WPGS, which can be addressed by applying one of the various Maximum Power Control methods [5, 6]. In order to optimize the operating state of the Aerodynamic Wind Systems (AWSs), it is necessary to include the MPPT algorithm to the AWSs. For this purpose, several papers on MPPT algorithm, with different control schemes from AWSs to extract the maximum energy from the variable wind speed, have been introduced in the literature. Such as [7], in which the authors conducted a critical analytical study of many papers published in this field, notably [8, 9]. Generally, there are four known MPPT methods called as Power Signal Feedback (PSF) [10]; Tip Speed 
Ratio (TSR) [11]; Optimum Torque (OT) [11] and Perturb and Observe (P\&O) [12] methods are used in WPGSs.

In [11], an analytical and comparative study between the TSR and OT algorithms is studied, where the authors concluded that the OT method required more improvement to achieve optimal operation of AWSs. To improve the efficiency of the OT-MPPT approach in AWSs, an OT-MPPT strategy based on the Fuzzy Logic Control (FLC) is implemented in [13, 14]. In [15], the authors suggested a Sliding Mode Control (SMC) for improving the WPGSs operation. In [16], Quantum Neural Network Control (QNNC) power optimization to improve the OT-MPPT method.

The operation of the AWS is controlled for operating within a specified range of wind speeds value limited by $V_{\text {ws-in }}$ and $V_{\text {ws-out }}$ speeds. Outside these values, the WTS must be shut down to protect it. Fig. 1 shows the operation areas of typical WTS [2].

It can be seen from Fig. 1 that there are four different operational areas. The first region is the low-wind area $\left(V<V_{\text {ws-in }}\right)$, where the turbine should not be operated and disconnected from the grid [17]. The second region is the partial load zone which is limited by the starting wind speed $\left(V_{w s-i n}\right)$ at which the WTS begins to operate, and the rated wind speed $\left(V_{\text {rated }}\right)$, where the WTS produces its nominal power $\left(V_{\text {ws-in }} \leq V<V_{\text {rated }}\right)$. In the high-speed region $\left(V_{\text {rated }} \leq V<V_{\text {ws-out }}\right.$ ), the power of the turbine is limited so that the WTS are not overloaded and dynamic loads do not cause mechanical failure [3]. This study focuses on the partial load operation, where the MPPT algorithm is required for optimal operation.

This study can be considered as a continuation of the above-mentioned studies. First a detailed model for representation of WTS dynamics simulations and the conventional method of OT-MPPT (CMPC-PI) is described. Then, this paper focuses attention on improving

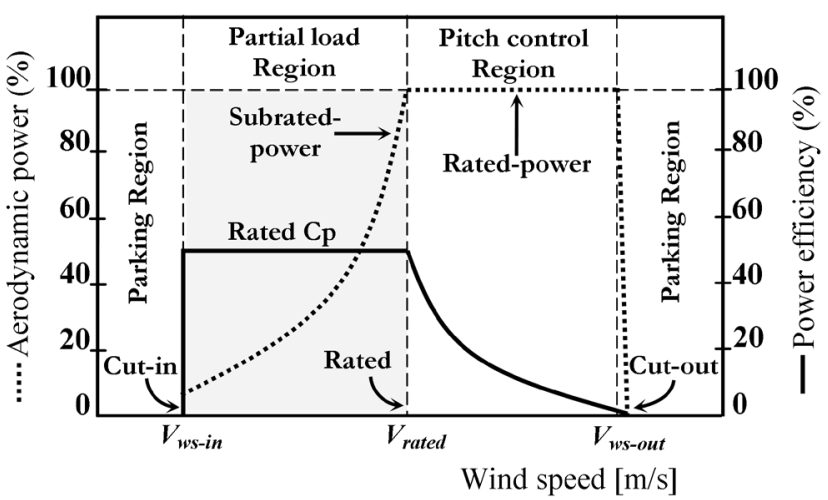

Fig. 1 Areas of operation of typical a WTS a method to allow better performances of the whole system in question during the partial load operation, using adaptive control theory. The proposed control objective is to follow the variable speed characteristics, which makes it feasible to search for maximum power point operation of the WTS below the rated wind speed. Instead of the conventional OT-MPPT algorithm referenced in [18, 19], an Optimum Torque method based on Adaptive Maximum Power Control is used in this work, as an effective solution for optimizing power conversion while reducing mechanical fatigue and output vibrations on the driveline. The main contribution of this study is the application of the Adaptive Maximum Power Control with Fuzzy-Logic as Adaption Mechanisms (AMPC-FLC technique) to the maximization of power with two different wind speed models.

\section{Wind speed modeling}

Wind speed generally has complex random variations, both deterministic effects (mean wind, tower shadow) and stochastic fluctuations over time due to turbulence. Generally, the deterministic and stochastic components are superimposed to form the following wind profile model [20], are (see Fig. 2):

$V(t)=V_{0}+\sum_{i=1}^{n} A_{i} \sin \left(\omega_{i} t+\varphi_{i}\right)$

where $V_{0}$ : mean component, $A_{i}:$ magnitude, $\omega_{i}$ : pulsation, $\varphi_{i}$ : initial phase of each turbulence.

As part of this work, we are interested only in much-localized wind, the wind swept over the area for a few seconds. In addition, to take into account the nature of wind turbulent, stochastic models are also used. The turbulence spectrum endorsed the distribution of turbulent

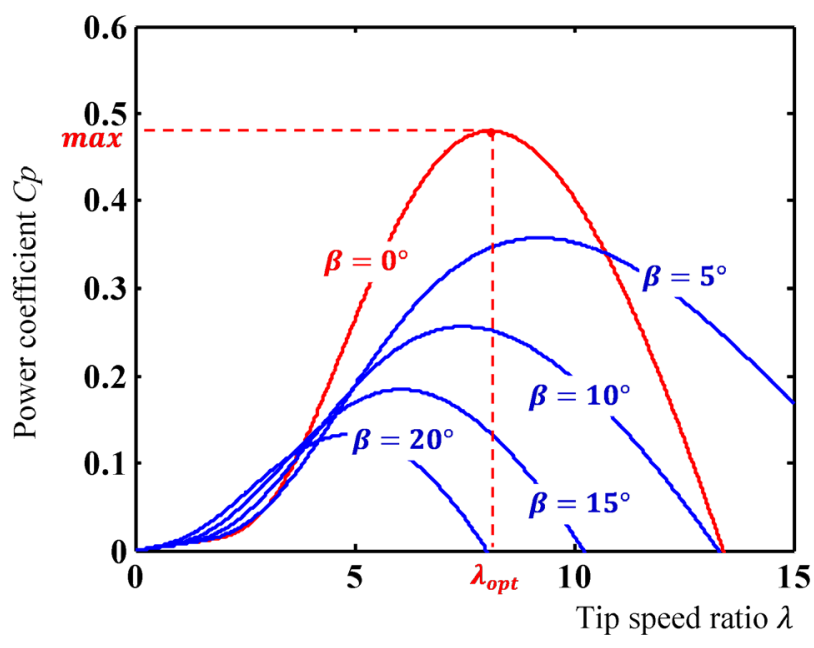

Fig. 2 Power coefficient variation against Tip Speed Ratio and pitch angle 
fluctuations energy, whose integral is determined by the intensity of the turbulence. The intensity of the turbulence is the following ratio:

$I=\sigma / V_{0}$ with the variance $\sigma^{2}=\frac{1}{T} \int_{0}^{T} v(t) d t$.

A Gaussian-process can generate a turbulent wind distribution. Therefore, the V-Karman-spectrum and one Kaimal-spectrum are the two models used, respecting the standards set by the International Electro-Technical Commission (IEC):

V-Karman-spectrum: $\varnothing(\omega)=\frac{K_{v}}{\left(1+(T \omega)^{2}\right)^{5 / 6}}$

Kaimal-spectrum: $\varnothing(\omega)=\frac{K_{v}}{|1+T \omega|^{5 / 3}}$,

where $K_{v}$ is a variable related to the variance $T$, which determines the turbulence bandwidth. The Danish RIS $\varnothing$ DTU laboratory for sustainable energy developed a wind model based Kaimal-spectrum. This model is implemented in MATLAB/Simulink $\AA$, where it is clearly presented in [21].

\section{Wind turbine modeling}

Based on the aerodynamic characteristics of the WTS, the quantity of energy captured by the system provided by the rotor is determined as follows [22]:

$P_{\text {aer }}=\frac{1}{2} C_{p}(\lambda, \beta) \rho \pi R^{2} V^{3}$,

where $\rho$ : air density, $R$ : blade length, $V$ : wind velocity.

The aerodynamic torque $T_{a e r}$ is expressed according to the aerodynamic power $P_{a e r}$ and the shaft speed $\Omega_{t}$ :

$T_{a e r}=\frac{P_{a e r}}{\Omega_{t}}$.

In WTS, the turbine usually associated to the generator shaft through a gearbox $G$. Ignoring the transmission losses, the shaft speed and torque of the WTS, referred to the gearbox on the generator side, are given by:

$T_{g}=T_{\text {aer }} / G ; \Omega_{t}=\Omega_{g} / G$,

where $\Omega_{g}$ : generator-shaft speed, $T_{g}$ : torque of the generator. Depending on the modeling turbine characteristics, the power coefficient $C_{P}$ (Betz's factor) can be represented by the following expression [23]:

$C_{p}=c_{1}\left(\frac{c_{2}}{\lambda_{i}}-c_{3} \beta-c_{4}\right) \exp \left(\frac{-c_{2}}{\lambda_{i}}\right)+c_{6} \lambda$, where $\frac{1}{\lambda_{i}}=\frac{1}{\lambda+0.08 \beta}-\frac{0.035}{\beta^{3}+1}$

with:

$\lambda=\frac{\Omega_{t} R}{V}$.

Fig. 2 shows a typical power coefficient $\left(C_{p}\right)$ versus curve for several values of pitch angle $(\beta)$ In a WTS, there is one optimal value of Tip Speed Ratio $\left(\lambda_{\text {opt }}\right)$ for the power coefficient to take its maximum, which is in the following position $\left(C_{p, \text { max }} \approx 0.479, \lambda_{\text {opt }} \approx 8.1\right)$ [24].

By using the Eq. (4), the shaft system dynamics is given as follows [1]:

$J \dot{\Omega}_{g}=T_{g}-T_{e m}-f_{v} \Omega_{g}$,

where $J$ : total moment of inertia, $f_{v}$ : coefficient of viscous friction and $T_{e m}$ : electromagnetic torque.

Fig. 3 shows typical characteristics that give the aerodynamic power of WPGS operating at variable speed as a function of different wind speed values.

Rearranging Eq. (2), the aerodynamic power can be described as:

$P_{a e r}=k_{t}(\beta) \Omega_{t}^{3}$,

where $k_{t}(\beta)=\frac{C_{p}(\beta) \rho \pi R^{5}}{2 \lambda^{3}}$.

The $P_{a e r} / \Omega_{t}$ gives the expression of the $T_{a e r}$. The turbine torque as a function of the speed characteristics of the turbine shaft at different wind speeds is shown in Fig. 4.

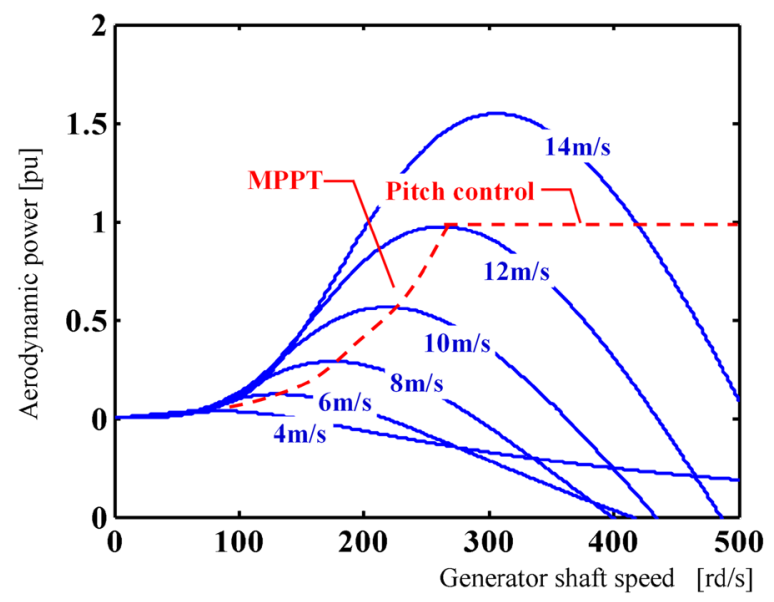

Fig. 3 Aerodynamic powers various speed characteristics with tracking curve 


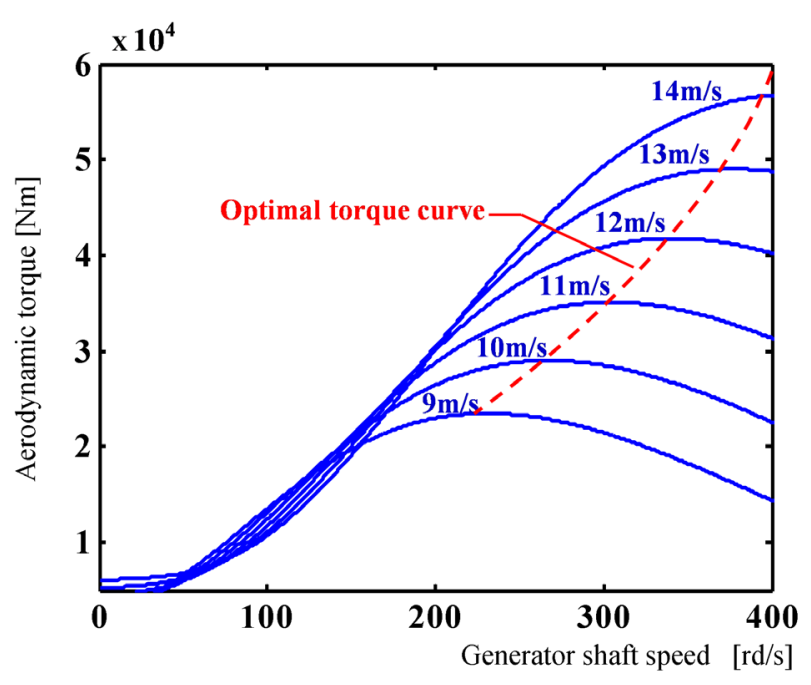

Fig. 4 Torque/speed characteristics of the WPGS

\section{MPC Based on Optimum Torque method}

As described in [25], a torque control (hence power) is designed to extract the maximum available wind power by adjusting the rotational speed of the generator shaft. The generator torque is controlled to obtain an Optimum Torque reference curve based on the wind turbine's maximum power at a given wind speed [5].

\subsection{Conventional MPC-PI}

This first mode configuration consists of adjusting the torque shown on the turbine shaft so as to set its speed to a reference [26]. In this context, it is considered that the electromagnetic-torque developed and their references are equal at all times, assuming that the electric machine and its static converter are ideal [19]:

$T_{e m}=T_{e m}^{*}$.

From the Eq. (7) it is clear that the generator speed is governed by the action of two torques, the torque coming out of the gearbox $T_{g}$ and the electromagnetic torque $T_{e m}$.

This relation also shows that to have a reference torque, it's necessary to have a reference generator speed, the rotational of the reference speed generator $\Omega_{g}^{*}$, which depends on the speed of the turbine, is obtained by Eq. (4) as follows:

$\Omega_{g}^{*}=G \Omega_{t}^{*}$.

This method of the first select mode is based on wind speed information. Supposing that the Tip Speed Ratio optimal value $\lambda_{\text {opt }}$ can be obtained from Fig. 2 , the optimal speed of the turbine can be given from Eq. (6):

$\Omega_{t, o p t}=\frac{\lambda_{o p t} V}{R}$.

To apply this control configuration, speed must be controlled by a Proportional Integral regulator (PI). In order to track the reference rotor speed, servo speed control using reference electromagnetic torque is used:

$T_{e m}^{*}=\left(\Omega_{g}^{*}-\Omega_{g}\right)\left[K_{p}+\frac{K_{i}}{s}\right]$.

Fig. 5 illustrates the CMPC-PI strategy block diagram.

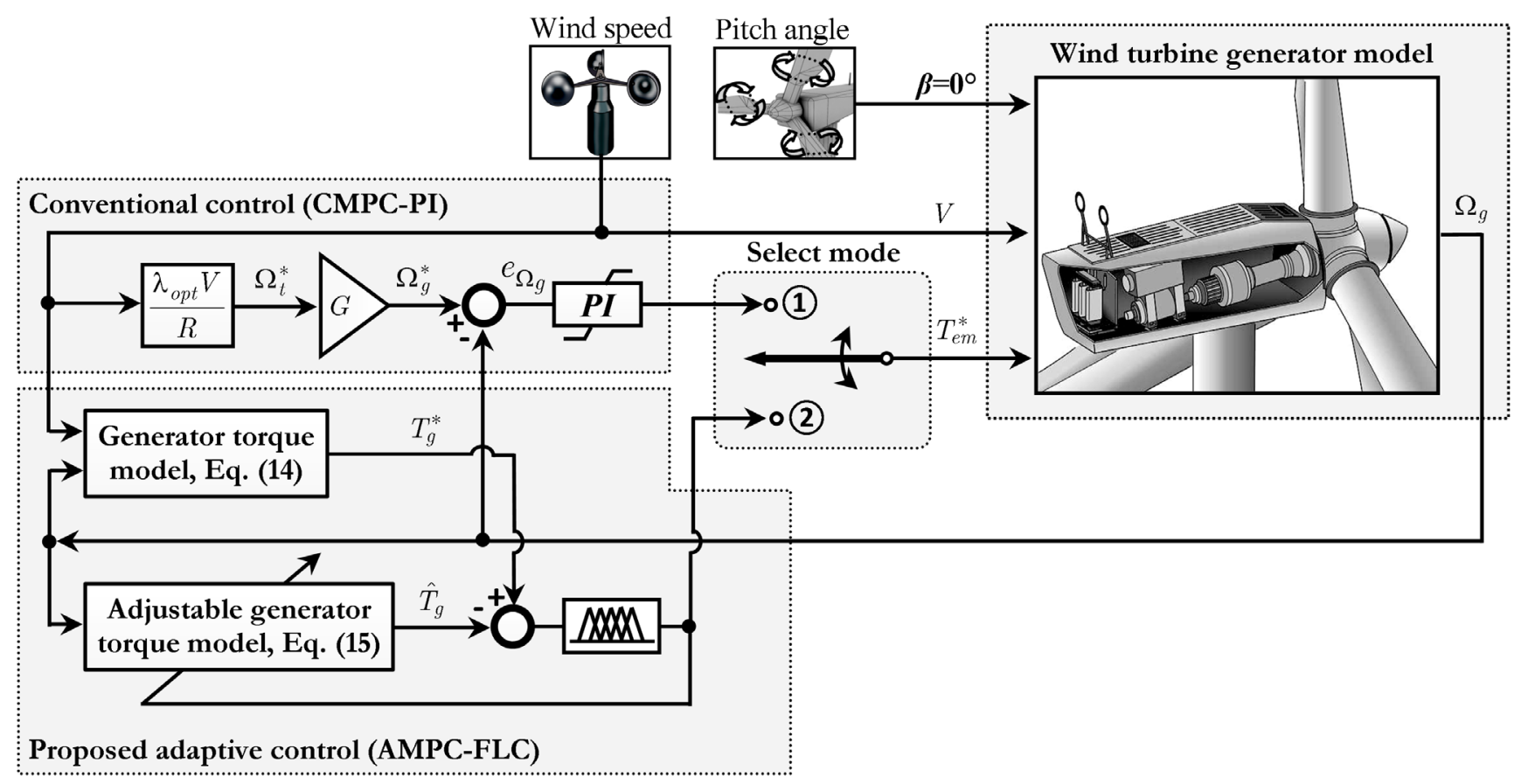

Fig. 5 WTS model and control structure with select mode: CMPC-PI (1), AMPC-FLC (2) 


\subsection{Proposed Adaptive MPC-FLC}

In the same operating principle as the MRAC approach (Model Reference Adaptive Control), the AMPC (Adaptive Maximum Power Control) is a kind of control methods that follows the response signal at the output of the reference model. It has simple, fast and stable structure advantages. The general idea of the AMPC technique is to incorporate a reference model to acquire the preferred closed loop reactions. AMPC designs the adaption mechanism and adjustments technique to drive the desired trajectories for the system to track the reference model output. The block diagram of the AMPC is shown in Fig. 6.

As seen from the figure, the AMPC technique consists of two independent models for estimating the identical parameter (generator torque). One is termed the reference model, and this model does not embody an estimated parameter, and the other is termed an adjustable model that depends entirely on the estimated parameter.

\subsubsection{Reference model}

From Eqs. (3) and (4), the generator torque model is:

$T_{g}^{*}=\frac{P_{\text {aer }, \text { opt }}}{\Omega_{g}}$.

Equations (2) and (5) can be used to express the reference generator torque model as:

$$
T_{g}^{*}=C_{p, \max }\left(\lambda_{o p t}, \beta\right) \frac{\rho \pi R^{2} V^{3}}{2 \Omega_{g}} .
$$

\subsubsection{Adjustable model}

According to dynamic Eq. (7), the adjustable generator torque model is expressed by:

$\hat{T}_{g}=J \frac{d \Omega_{g}}{d t}+f_{v} \Omega_{g}+\hat{T}_{e m}$.

\subsubsection{Adaption mechanism}

The Adaption algorithm (FLC) is chosen so as to converge the adjustable model to the reference model by minimizing the error and having a stability of the system.

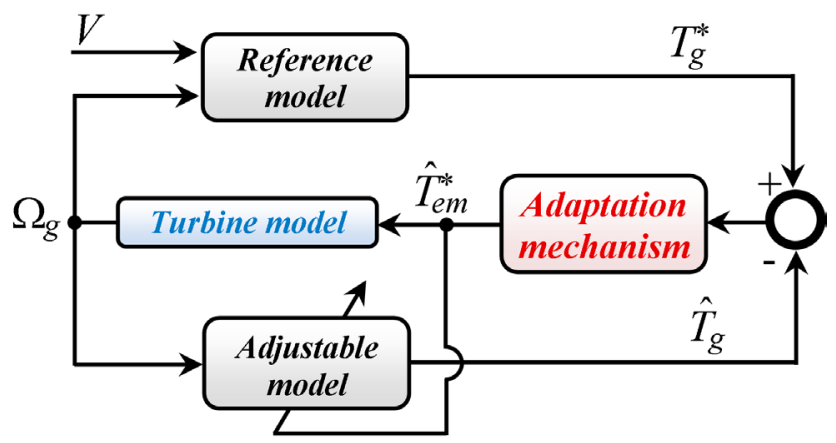

Fig. 6 Proposed Adaptive Maximum Power Control scheme
Due to the robustness of the fuzzy logic for many non-linear processes, this paper proposes the design of fuzzy logic with the Mamdani-fuzzy inference system [27]. Fig. 7 shows a fuzzy controller block diagram.

The input/output linguistic variables of the fuzzy controller were quantized in the following five fuzzy subsets. Table 1 shows the fuzzy governing rules used in this work base with 25 rules which can be obtained from observation of the control performance at different operating points, where the input variables are: $e$ : error, de: derived from the error. The inputs and outputs scaling gains are: $K_{e}, K_{d e}$ and $K_{u}$.

For the proposed FLC of the Adaption mechanism, we use the block diagram of Fig. 7, there are two input signals to the FLC, the first input related to the error between the reference model and the adjustable model. The second one relates to the variation of this error. These two signals are expressed by:

$\left\{\begin{array}{l}e_{T_{g}}(n)=T_{g}^{*}(n)-\hat{T}_{g}(n) \\ \Delta e_{T_{g}}(n)=T_{g}^{*}(n)-\hat{T}_{g}(n-1)\end{array}\right.$.

The fuzzy sets have been determined as; Negative Large (NL), Negative Small (NS), Zero (ZE), Positive Small (PS), Positive Medium (PM) and Positive Large (PL).

The input/output variables used in this study are evaluated and fuzzified by triangular symmetrical Membership Functions (MFs) (Fig. 8 (a), (b) and (c)) normalized in the universe of discourse between -1 and +1 . The FLCsurface was presented in Fig. 8 (d). Then, the outputs of our fuzzy-controller are $T_{e m}^{*}$. The WTS operated well and achieved the MPPT curve during a partial load operation. The reference electromagnetic torque $T_{e m}^{*}$ will be an input

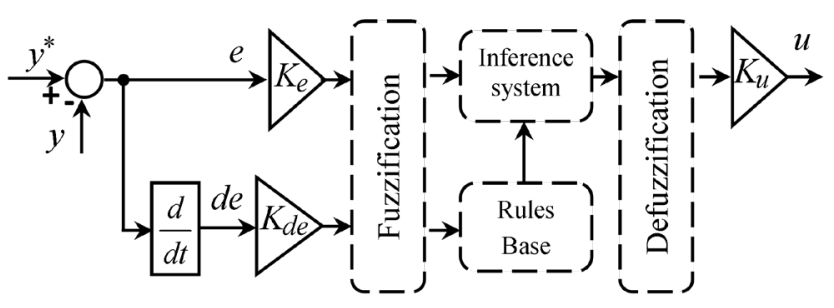

Fig. 7 Fuzzy controller block diagram structure

Table 1 Fuzzy rule base for the controller

\begin{tabular}{llllll}
\hline & & \multicolumn{5}{c}{$e$} \\
\hline de & NL & NS & ZE & PS & PL \\
NL & NL & NL & NL & NS & ZE \\
NS & NL & NS & NS & ZE & PS \\
$\mathbf{Z E}$ & NL & NS & ZE & PS & PL \\
PS & NS & ZE & PS & PS & PL \\
PL & ZE & PS & PL & PL & PL \\
\hline
\end{tabular}




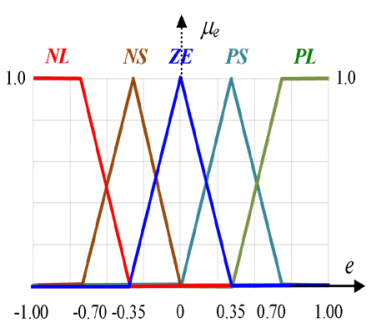

(a)

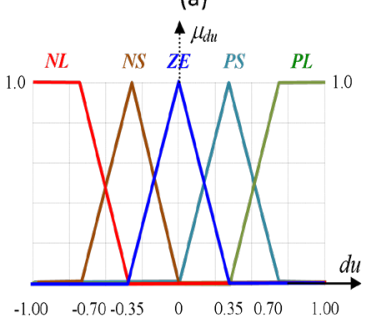

(c)

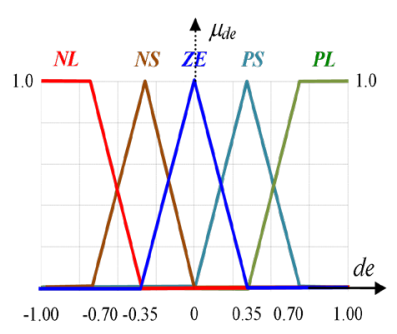

(b)

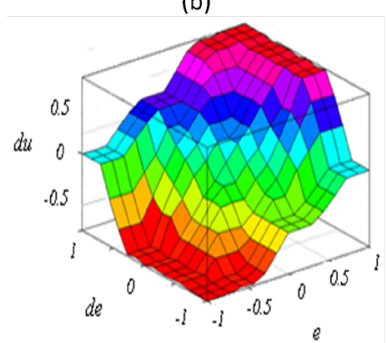

(d)
Fig. 8 FLC input/output memberships of the: (a) Error, (b) Error variation, (c) Command variation, (d) Control surface

for the control loop described in this section. It should be noted that this study focuses on the MPPT. Accordingly, the AMPC-FLC of our system is shown in Fig. 5 (Second select mode).

\section{Simulation results and discussion}

Some results of the simulation of the two select mode of power control were carried out on the MATLAB/Simulink ${ }^{\circledR}$ platform. All simulations have been developed with a fixed step size of 0.1 [ms] with a view to digital implementation in future works.

The first wind speed profile utilized in this simulation, shown in Fig. 9 (a), relies on Eq. (1). Though it's not usually the case in point of fact, this form is extremely frequently utilized in simulations studies, because it's straightforward to use and shows the worst case. Additionally, the second wind profile based on the RISØ model is shown in Fig. 9 (b). The following simulation results are performed to compare the two select mode control, namely, the classical method (CMPC-PI) and the proposed Adaptive Maximum Power Control (AMPC-FLC) algorithm (see Fig. 5).

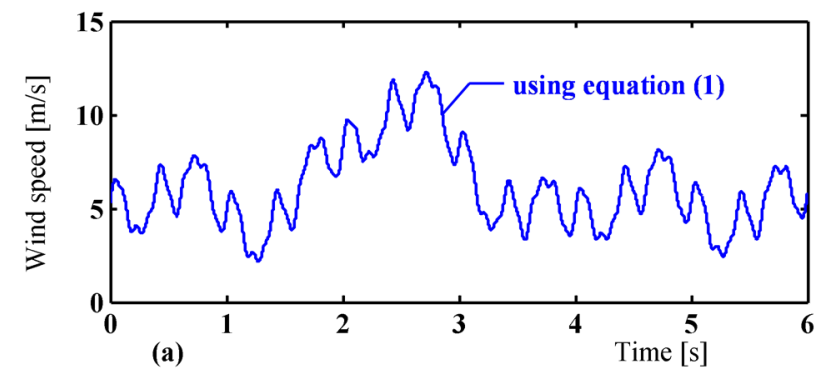

In order to demonstrate the robustness and to verify the effectiveness of our proposed approach, a step-noise of magnitude 25, uncertainties in the WTS are under the influence of a white noise added to the turbine torque. These kinds of noise will embody un-modeled quantities, parametric uncertainties and external disturbances. Fig. 10 illustrates the dynamic performance of the WTS based on wind speed using the Eq. (1), while, Fig. 11 shows the performance of the our system underneath the identical conditions based on wind speed using RIS $\varnothing$ model during partial load operation.

The generator-shaft-speed using the two select mode control for the two wind profiles used, are shown in Fig. 10 (a) and Fig. 11 (a), which is proportional to the wind speed curve. It may be seen from these figures that the proposed control configuration curve mediates the curves of the conventional configurations, this proposed AMPC-FLC strategy has better response characteristics in settling time and overshoot as compared with both CMPC-PI.

Figs. 10 (b), (d) and 11 (b), (d) show, respectively, the generator and aerodynamic torque obtained by using two different wind speed models. As indicated in Eq. (4), it can be seen that the variations of the generator torque are perfectly adapted to the variation of the aerodynamic torque.

From an energy point of view for the two wind speed profiles used, Figs. 10 (c) and 11 (c) show the aerodynamic power obtained by the two control methods. These results show the predominance of energy production by using the proposed AMPC-FLC method over the classical CMPC-PI method.

It can be seen from Figs. 10 (e) and 11 (e) that the proposed AMPC-FLC configuration is an efficient MPPT technique, tracking optimal power points, keeping the power coefficient around its maximum value $\left(C_{p, \max } \approx 0.479\right)$ with less oscillations. It is also shown in these figures that the Tip Speed Ratio is around its optimum value $\left(\lambda_{\text {opt }} \approx 8.1\right)$ with less oscillation. Therefore, this AMPC-FLC proposed technique is also considered a soft and robust control, which is proven in these results, with an improvement in dynamic performance. Taking a comparative approach, it can be

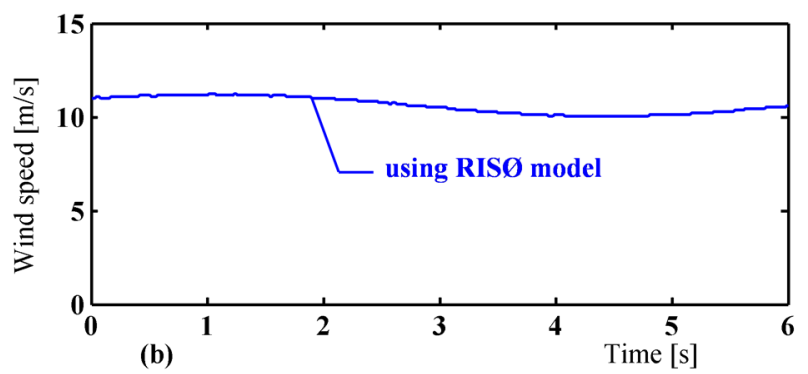

Fig. 9 Wind speed profile 


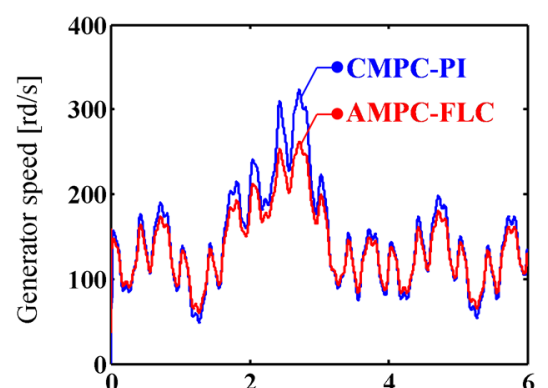

(a)

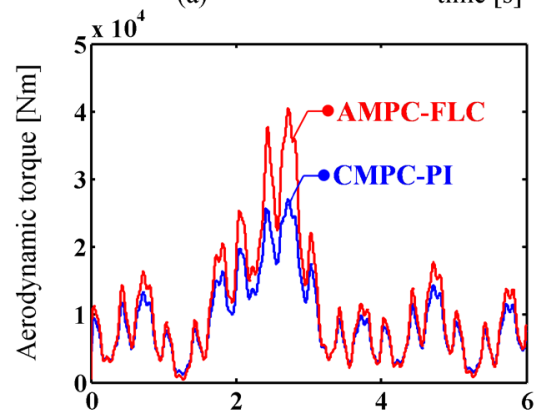

(d)

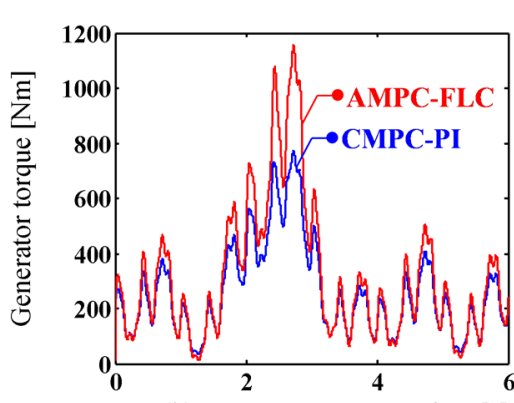

(b)

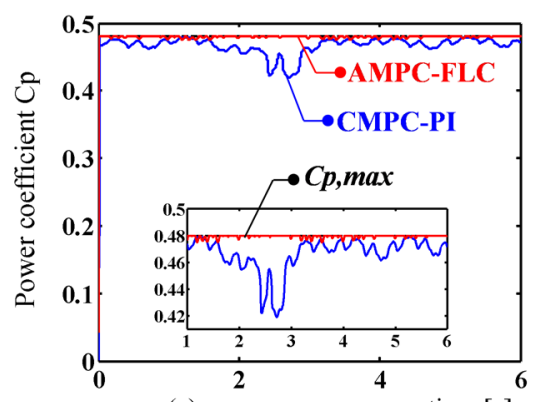

(e)

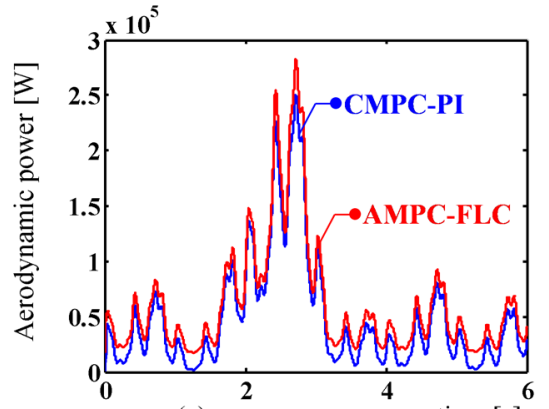

(c)

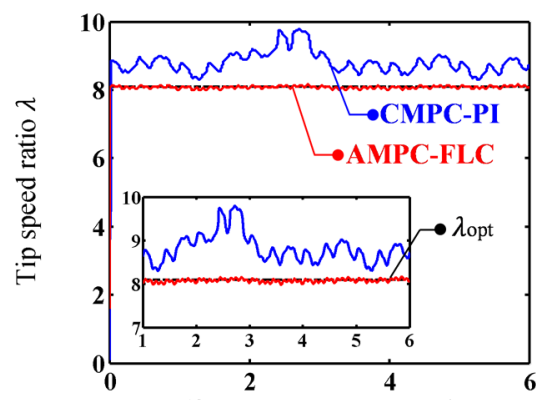

(f) time $[\mathrm{s}]$

Fig. 10 WTS performance based on wind speed using Eq. (1)

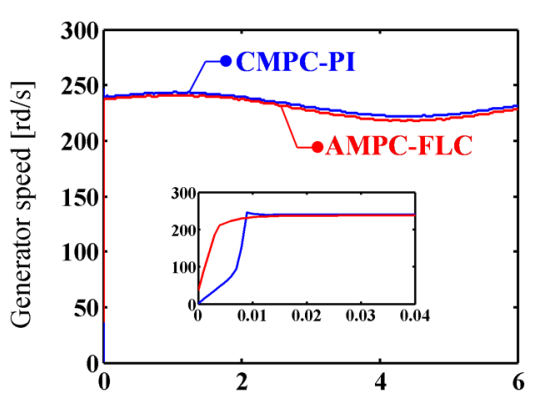

(a)

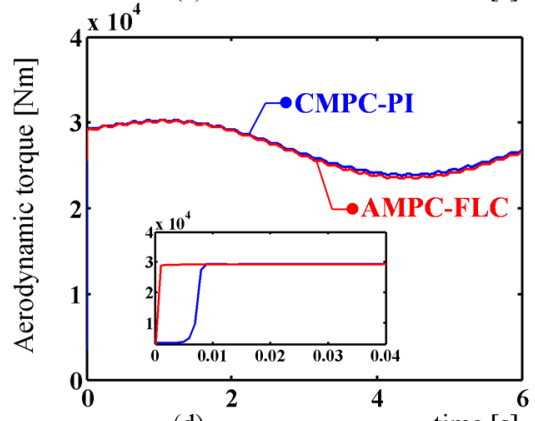

(d)

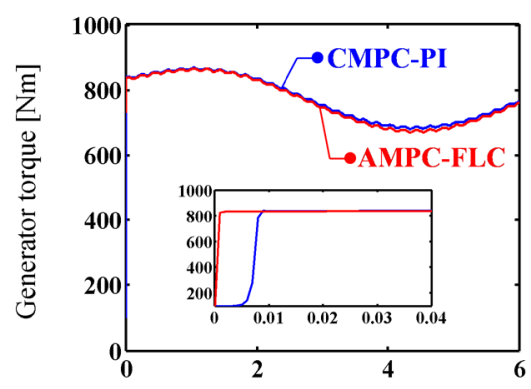

(b)

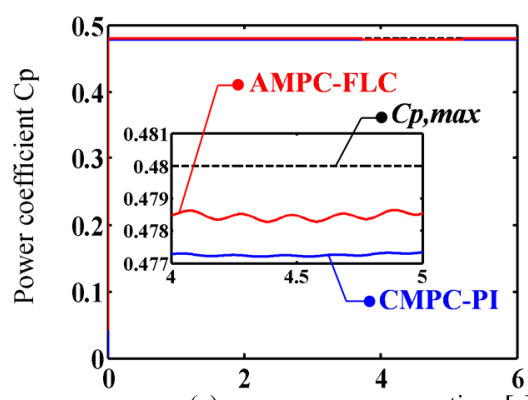

(e)

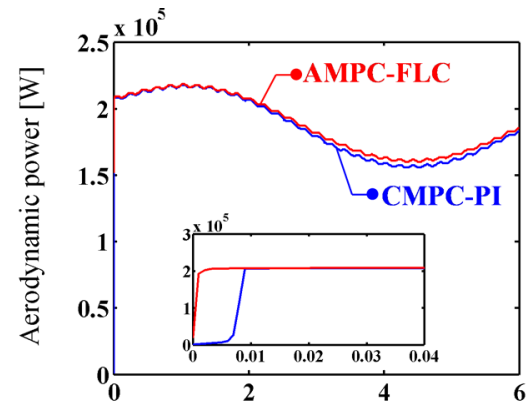

(c)

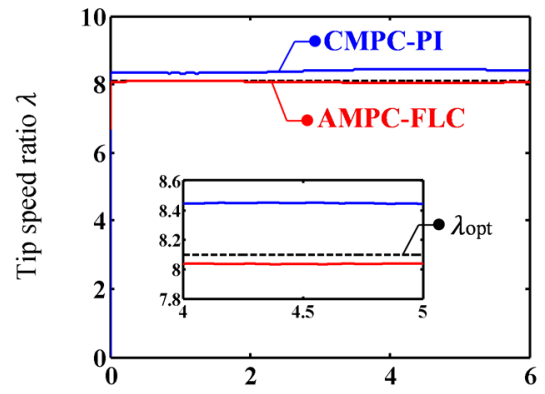

(f)

Fig. 11 WTS performance based on wind speed RISØ model

deduced from these simulation results that the oscillations of power coefficient and Tip Speed Ratio are responsible for the mechanical stresses under the CMPC-PI method.

\section{Conclusions}

In this paper, the proposed Adaptive Maximum Power Control using Fuzzy-Logic as Adaption Mechanisms (AMPC-FLC) is designed for the WTSs based on
Optimum Torque (OT) method during partial load operation in order to capture the maximum power of the wind. The randomly varying wind speeds can affect the WTS efficiency and lead to drive-train mechanical-stresses. Hence, the control strategy of the wind turbine is required to guarantee robustness against this impact. The AMPCFLC proposed algorithm is in a position to actively follow the generator shaft speed in quick dynamic changes under 
system uncertainties, the proposed method is effective for real-time electromagnetic torque control under severe randomly varying wind speed and disturbance rejection. This approach was compared with the classical CMPC-PI method and validated by simulation.

For some simulation results, the proposed AMPCFLC is an improvement over conventional method,

\section{References}

[1] Saidi, Y., Mezouar, A., Miloud, Y., Benmahdjoub, M. A. "A Robust Control Strategy for Three Phase Voltage t Source PWM Rectifier Connected to a PMSG Wind Energy Conversion System", In: 2018 International Conference on Electrical Sciences and Technologies in Maghreb (CISTEM), Algiers, Algeria, 2018, pp. 1-6. https://doi.org/10.1109/CISTEM.2018.8613359

[2] Anaya-Lara, O., Jenkins, N., Ekanayake, J. B., Cartwright, P., Hughes, M. "Wind Energy Generation: Modelling and Control", John Wiley \& Sons, West Sussex, UK, 2011.

[3] Saidi, Y., Mezouar, A., Miloud, Y., Yahiaoui, M., Benmahdjoub, M. A. "Modeling and Adaptive Power ControlDesigned based on Tip Speed Ratio method for Wind Turbines", Przegląd Elektrotechniczny, 95(6), pp. 40-46, 2019. https://doi.org/10.15199/48.2019.06.08

[4] Nadhir, A., Hiyama, T. "Maximum Power Point Tracking Based Optimal Control Wind Energy Conversion System", In: 2010 Second International Conference on Advances in Computing, Control, and Telecommunication Technologies, Jakarta, Indonesia, 2010, pp. 41-44. https://doi.org/10.1109/ACT.2010.38

[5] Kumar, D., Chatterjee, K. "A review of conventional and advanced MPPT algorithms for wind energy systems", Renewable and Sustainable Energy Reviews, 55, pp. 957-970, 2016. https://doi.org/10.1016/j.rser.2015.11.013

[6] Kara, Z., Barra, K. "Hybrid Controller for Variable Speed Wind Energy Conversion System with Slip Energy Recovery Using Matrix Converter Topology", Periodica Polytechnica Electrical Engineering and Computer Science, 59(4), pp. 160-174, 2015. https://doi.org/10.3311/PPee.8507

[7] Kazmi, S. M. R., Goto, H., Guo, H. J., Ichinokura, O. "Review and critical analysis of the research papers published till date on maximum power point tracking in wind energy conversion system", In: 2010 IEEE Energy Conversion Congress and Exposition, Atlanta, GA, USA, 2010, pp. 4075-4082. https://doi.org/10.1109/ECCE.2010.5617747

[8] Kazmi, S. M. R., Goto, H., Guo, H. J., Ichinokura, O. "A Novel Algorithm for Fast and Efficient Speed-Sensorless Maximum Power Point Tracking in Wind Energy Conversion Systems", IEEE Transactions on Industrial Electronics, 58(1), pp. 29-36, 2011. https://doi.org/10.1109/TIE.2010.2044732

[9] Hui, J., Bakhshai, A. "A new adaptive control algorithm for maximum power point tracking for wind energy conversion systems", In: 2008 IEEE Power Electronics Specialists Conference, Rhodes, Greece, 2008, pp. 4003-4007. https://doi.org/10.1109/PESC.2008.4592580 demonstrating high robustness, accuracy of pursuit the maximum conversion efficiency and skill to scale back mechanical stresses. Therefore, the mechanical working life is extended without significantly increasing the complexity of the control.

[10] Barakati, S. M., Kazerani, M., Aplevich, J. D. "Maximum Power Tracking Control for a Wind Turbine System Including a Matrix Converter", IEEE Transactions on Energy Conversion, 24(3), pp. 705-713, 2009. https://doi.org/10.1109/TEC.2008.2005316

[11] Nasiri, M., Milimonfared, J., Fathi, S. H. "Modeling, analysis and comparison of TSR and OTC methods for MPPT and power smoothing in permanent magnet synchronous generator-based wind turbines", Energy Conversion and Management, 86, pp. 892-900, 2014. https://doi.org/10.1016/j.enconman.2014.06.055

[12] Abdullah, M. A., Yatim, A. H. M., Tan, C. W., Saidur, R. "A review of maximum power point tracking algorithms for wind energy systems", Renewable and Sustainable Energy Reviews, 16(5), pp. 3220-3227, 2012.

https://doi.org/10.1016/j.rser.2012.02.016

[13] Eltamaly, A. M., Farh, H. M. "Maximum power extraction from wind energy system based on fuzzy logic control", Electric Power Systems Research, 97, pp. 144-150, 2013. https://doi.org/10.1016/j.epsr.2013.01.001

[14] El Yaakoubi, A., Asselman, A., Djebli, A., Aroudam, E. H. "A MPPT Strategy Based on Fuzzy Control for a Wind Energy Conversion System", Procedia Technology, 22, pp. 697-704. 2016. https://doi.org/10.1016/j.protcy.2016.01.145

[15] Zheng, X., Li, L., Xu, D., Platts, J. "Sliding Mode MPPT Control of Variable Speed Wind Power System", In: 2009 Asia-Pacific Power and Energy Engineering Conference, Wuhan, China, 2009, pp. 1-4. https://doi.org/10.1109/APPEEC.2009.4918770

[16] Ganjefar, S., Ghassemi, A. A., Ahmadi, M. M. "Improving efficiency of two-type maximum power point tracking methods of tip-speed ratio and optimum torque in wind turbine system using a quantum neural network", Energy, 67, pp. 444-453, 2014. https://doi.org/10.1016/j.energy.2014.02.023

[17] Muyeen, S. M. "Wind Energy Conversion Systems: Technology and Trends", Springer, London, UK, 2012. https://doi.org/10.1007/978-1-4471-2201-2

[18] Kerrouche, K., Mezouar, A., Boumedien, L. "A simple and efficient maximized power control of DFIG variable speed wind turbine", In: 3rd International Conference on Systems and Control, Algiers, Algeria, 2013, pp. 894-899. https://doi.org/10.1109/ICoSC.2013.6750963

[19] Chauhan, S., Sameeullah, M., Dahiya, R. "Maximum Power Point Tracking scheme for variable speed wind generator", In: 2014 IEEE 6th India International Conference on Power Electronics, Kurukshetra, India, 2014, pp. 1-5. https://doi.org/10.1109/IICPE.2014.7115798 
[20] Kerrouche, K. D. E., Mezouar, A., Boumediene, L., Belgacem, K. "Modeling and Optimum Power Control Based DFIG Wind Energy Conversion System", International Review of Electrical Engineering (IREE), 9(1), pp. 174-185, 2014.

https://doi.org/10.15866/iree.v9i1.118

[21] Iov, F., Hansen, A. D., Sørensen, P. E., Blaabjerg, F. "Wind Turbine Blockset in Matlab/Simulink: General Overview and Description of the Models", Aalborg University, Aalborg, Denmark, RISØ National Laboratory, Roskilde, Denmark, Rep. NEI-DK-4424, 2004.

[22] Benbouhenni, H., Boudjema, Z., Belaidi, A. "Using Four-Level NSVM Technique to Improve DVC Control of a DFIG Based Wind Turbine Systems", Periodica Polytechnica Electrical Engineering and Computer Science, 63(3), pp. 144-150, 2019.

https://doi.org/10.3311/PPee.13636

[23] Saidi, Y., Mezouar, A., Miloud, Y., Benmahdjoub, M. A., Yahiaoui, M. "Fuzzy Logic Based Robust DVC Design of PWM Rectifier Connected to a PMSG WECS under wind/load Disturbance Conditions", International Journal of Energetica (IJECA), 4(1), pp. 37-43, 2019. [online] Available at: https://www. ijeca.info/index.php/IJECA/article/view/84/77 [Accessed: 19 October 2019]

[24] Rahmanian, E., Akbari, H., Sheisi, G. H. "Maximum Power Point Tracking in Grid Connected Wind Plant by Using Intelligent Controller and Switched Reluctance Generator", IEEE Transactions on Sustainable Energy, 8(3), pp. 1313-1320, 2017.

https://doi.org/10.1109/TSTE.2017.2678679

\section{Appendix}

In this part, simulations are investigated with a $1.5 \mathrm{MW}$ generator WTS [28]. The parameters of our system are presented in Table 2.

Table 2 Parameters of WT Generator

\begin{tabular}{ccc}
\hline$\rho=1.22 \mathrm{Kg} / \mathrm{m}^{3}$ & $G=90$ & $R=35.25 \mathrm{~m}$ \\
\hline$J=1000 \mathrm{Kg} \cdot \mathrm{m}^{2}$ & $\beta=0 \mathrm{deg}$ & $f_{v}=0.0024 \mathrm{Kg} \cdot \mathrm{m} / \mathrm{s}$ \\
$C_{1}=0.5176$ & $C_{2}=116$ & $C_{3}=0.4$ \\
$C_{4}=5$ & $C_{5}=21$ & $C_{6}=0.0068$ \\
\hline
\end{tabular}

[25] Ghoudelbourk, S., Dib, D., Omeiri, A., Azar, A. T. "MPPT control in wind energy conversion systems and the application of fractional control $\left(\mathrm{PI}^{\alpha}\right)$ in pitch wind turbine", International Journal of Modelling, Identification and Control (IJMIC), 26(2), pp. 140-151, 2016. https://doi.org/10.1504/ijmic.2016.078329

[26] Saidi, Y., Mezouar, A., Miloud, Y., Benmahdjoub, M. A., Yahiaoui, M. "Modeling and Comparative Study of Speed Sensor and Sensor-less based on TSR-MPPT Method for PMSG-WT Applications", International Journal of Energetica (IJECA), 3(2), pp. 6-12, 2018. [online] Available at: https://www.ijeca.info/index. php/IJECA/article/view/69/64 [Accessed: 19 October 2019]

[27] Mamdani, E. H., Assilian, S. "An Experiment in Linguistic Synthesis with a Fuzzy Logic Controller", International Journal of Human-Computer Studies, 51(2), pp. 135-147, 1999. https://doi.org/10.1006/ijhc.1973.0303

[28] Saidi, Y., Mezouar, A., Miloud, Y., Kerrouche, K. D. E., Brahmi, B., Benmahdjoub, M. A. "Advanced non-linear backstepping control design for variable speed wind turbine power maximization based on tip-speed-ratio approach during partial load operation", International Journal of Dynamics and Control, 2019. https://oi.org/10.1007/s40435-019-00564-3 